\title{
INSPIRATORY CAPACITY-TO-TOTAL LUNG CAPACITY RATIO AND DYSPNOEA PREDICT EXERCISE CAPACITY DECLINE IN COPD
}

Maria A Ramon, ${ }^{1,2,3}$ Jaume Ferrer, ${ }^{1,2,3}$ Elena Gimeno-Santos, ${ }^{4,5,6}$ David DonaireGonzalez, ${ }^{4,5,6}$ Esther Rodríguez, ${ }^{1,2,3}$ Eva Balcells, ${ }^{3,6,7,8}$ Jordi de Batlle, ${ }^{4,9}$ Marta Benet, ${ }^{4,5,6}$ Stefano Guerra, ${ }^{4,5,6}$ Jaume Sauleda, ${ }^{10}$ Antoni Ferrer, ${ }^{3,6,7,8,11}$ Eva Farrero, ${ }^{12,13}$ Joaquim Gea, ${ }^{3,6,7,8}$ Joan A Barberà, ${ }^{3,14}$ Alvar Agustí, ${ }^{3,14}$ Robert Rodriguez-Roisin, ${ }^{3,14}$ Josep M Antó, ${ }^{4,5,6,7}$ Judith Garcia-Aymerich, ${ }^{4,5,6}$ and the PAC-COPD Study Group.

${ }^{1}$ Department of Pneumology, Hospital Universitari Vall d'Hebron, Barcelona, Spain. ${ }^{2}$ Departament de Medicina, Universitat Autònoma de Barcelona, Barcelona, Spain. ${ }^{3}$ CIBER de Enfermedades Respiratorias (CIBERES), Barcelona, Spain. ${ }^{4}$ Centre for Research in Environmental Epidemiology (CREAL), Barcelona, Spain. ${ }^{5}$ CIBER Epidemiología y Salud Pública (CIBERESP), Barcelona, Spain. ${ }^{6}$ Universitat Pompeu Fabra (UPF), Barcelona, Spain. ${ }^{7}$ IMIM (Hospital del Mar Medical Research Institute), Barcelona, Spain. ${ }^{8}$ Department of Pneumology, Hospital del Mar, Barcelona, Spain. ${ }^{9}$ Section of Nutrition and Metabolism, International Agency for Research on Cancer, Lyon, France. ${ }^{10}$ Department of Pneumology, Hospital Universitari Son Espases, Institut d'Investigació Sanitària de Palma (IdISPa), Palma Mallorca, Spain. ${ }^{11}$ Department of Pneumology. Hospital de Sabadell. Corporació Parc Taulí, Sabadell, Spain. ${ }^{12}$ Department of Pneumology, Hospital Universitari de Bellvitge, Barcelona, Spain. ${ }^{13}$ Institut d'Investigació Biomèdica de Bellvitge (IDIBELL), Barcelona, Spain. ${ }^{14}$ Servei de Pneumologia (Thorax Institute), Hospital Clínic, Institut d'Investigacions 
Biomèdiques August Pi i Sunyer (IDIBAPS), Universitat de Barcelona, Barcelona, Spain.

Corresponding author: Judith Garcia-Aymerich, Centre for Research in Environmental Epidemiology (CREAL), Dr. Aiguader 88, 08003 Barcelona - Spain; Telephone +34 93 21473 50; Fax + 349321473 02; E-mail: jgarcia@creal.cat

Abstract word count: 245

Text word count: 2,546 


\section{SUMMARY AT A GLANCE}

In clinically stable COPD patients, IC/TLC and dyspnoea, but not forced spirometric parameters, predict exercise capacity decline. This may help to screen candidates for early therapeutic interventions, including pulmonary rehabilitation. 


\section{ABSTRACT}

Background and objective: Exercise capacity decline is a predictor of mortality in patients with chronic obstructive pulmonary disease (COPD). Static pulmonary hyperinflation is a key determinant of exercise performance, but its effect on the longitudinal decline in exercise capacity remains unknown. We aimed to study the relationship between the inspiratory capacity-to-total lung capacity (IC/TLC) ratio and exercise capacity decline in COPD.

Methods: We measured IC/TLC and other relevant clinical and functional variables in 342 clinically stable COPD patients. The 6-minute walk distance (6MWD) was determined at recruitment and after a mean $\pm \mathrm{SD}$ of $1.7 \pm 0.3$ years. The annual rate of change in 6MWD was calculated. Multiple imputation to account for losses during follow-up was implemented and multivariate regression was used to analyse predictive factors of 6MWD decline.

Results: Mean decline rate in the 6MWD was $21.9 \pm 34.1 \mathrm{~m} / \mathrm{y}$. In the bivariate analysis, patients with lower levels of IC/TLC had greater 6MWD decline (-27.4 442.5 , $24.9 \pm 36.5$ and $-13.4 \pm 39.9 \mathrm{~m} /$ year in the $1^{\text {st }}, 2^{\text {nd }}$ and $3^{\text {rd }}$ tertile of IC/TLC, respectively; $\mathrm{p}$-for-trend $=0.018$ ). From other potential risk factors considered, dyspnoea, health status, serum C-reactive protein and Borg dyspnoea score at the end of the exercise test were related to exercise capacity decline. In the multivariate regression model, only IC/TLC $(\beta=0.7 \mathrm{~m} / \mathrm{y}$ per each percentage unit of IC/TLC; $\mathrm{p}=0.007)$ and dyspnoea $(\mathrm{mMRC} \geq 2)(\beta=-14.6 \mathrm{~m} / \mathrm{y} ; \mathrm{p}=0.013)$ were associated with the annual rate of $6 \mathrm{MWD}$ change.

Conclusions: IC/TLC and dyspnoea in clinically stable COPD patients predict their exercise capacity decline and may help to guide early therapeutic interventions. 
KEYWORDS: Cohort study; COPD; Disease progression; Exercise capacity; Sixminute walk distance.

SHORT TITLE: IC/TLC and dyspnoea predict 6MWD decline. 


\section{LIST OF ABBREVIATIONS}

BMI: body mass index

COPD: chronic obstructive pulmonary disease

DL $\mathbf{C O}_{\text {: }}$ diffusing capacity for carbon monoxide

$\mathbf{F E V}_{\mathbf{1}}$ : forced expiratory volume in $1 \mathrm{~s}$

GOLD: Global Initiative for Chronic Obstructive Lung Disease

IC: inspiratory capacity

MEP: maximum expiratory pressures

MIP: maximum inspiratory pressures

mMRC: Modified Medical Research Council dyspnoea scale

$\mathbf{P a O}_{2}$ : arterial oxygen tension

RV: residual volume

SGRQ: Saint George's respiratory questionnaire

TLC: total lung capacity

6MWT: 6-minute walk test

6MWD: 6-minute walk distance 


\section{INTRODUCTION}

Patients with chronic obstructive pulmonary disease (COPD) frequently suffer a limitation of their exercise capacity, ${ }^{1}$ which is multifactorial and results from complex interactions between physical, both pulmonary and non-pulmonary, and psychological factors. $^{2-4}$ Exercise capacity limitation worsens health status and reduces survival. ${ }^{5,6}$ Furthermore, exercise capacity often declines over time. ${ }^{7-10}$ This decline appears to be independent of longitudinal changes in airflow limitation ${ }^{9,10}$ and it is a strong predictor of mortality. ${ }^{8-10}$ Finally, exercise capacity decline can be prevented with therapeutic strategies including pulmonary rehabilitation. ${ }^{11}$ Therefore, it is important to identify what factors are associated with exercise capacity decline in COPD.

To date, only a few studies have investigated risk factors associated with exercise capacity decline in COPD, mainly using the 6-minute walk test (6MWT) as an index of exercise capacity. ${ }^{7,12,13}$ These studies identified that older age, ${ }^{4}$ lower body mass index $(\mathrm{BMI}){ }^{4}$ more severe airflow limitation $\left(\mathrm{FEV}_{1}\right)^{4,7,12}$ and a lower level of regular physical activity $^{12}$ were related to exercise capacity deterioration. However, these previous studies $^{7,12,13}$ suffered from varying proportions of losses during follow-up, which conditions their results to a certain degree of bias due to selective attrition. ${ }^{14}$ Nowadays statistical methods are available to account for missing values during follow-up, thus increasing the accuracy of estimated statistical associations. ${ }^{15}$

Moreover, the relationship between lung hyperinflation, a variable contributing to dyspnoea, morbidity and mortality in COPD,${ }^{16-18}$ and exercise capacity decline has not 
been reported in any of the of the abovementioned studies. ${ }^{7,12,13}$ Inspiratory capacity-tototal lung capacity (IC/TLC) ratio, a static hyperinflation-derived variable reflecting the mechanical inspiratory constraint, has been shown to be an important predictor of exercise performance in cross-sectional studies ${ }^{16,19-21}$. Therefore, IC/TLC might be a determinant of exercise capacity deterioration in COPD.

We hypothesised that IC/TLC can be a predictor of the decline in exercise capacity in COPD patients and tested this contention in 342 COPD patients prospectively followedup in the "Phenotype and Course of COPD (PAC-COPD)" Study. ${ }^{22}$ 


\section{METHODS}

\section{Study design and participants}

Subjects were recruited during their first hospitalisation due to a COPD exacerbation in 9 teaching hospitals in Spain between January 2004 and March 2006. The diagnosis of COPD (post-bronchodilator forced expiratory volume in the first second to forced vital capacity ratio $\left.\left(\mathrm{FEV}_{1} / \mathrm{FVC}\right)<0.70\right)$ was confirmed in stable clinical conditions, at least 3 months after discharge, during a first evaluation visit. ${ }^{23}$ Following the original protocol, 18 to 24 months (2006-2008) after this first visit, patients were invited to participate in a second evaluation for follow-up assessment. Of the 342 patients originally recruited into the PAC-COPD study ${ }^{24} 226(66 \%)$ had measures of exercise capacity in the two evaluation visits. Subjects lost to follow-up were older, had more co-morbidities and lower $\mathrm{FEV}_{1}$, as reported elsewhere. ${ }^{25}$ The Clinical Research Ethical Committee of each centre approved the study and written informed consent was obtained from all participants.

\section{Measurements}

Exercise capacity was assessed by the $6 \mathrm{MWT}^{26}$ In the first visit, patients completed two tests with at least a 30-min rest between them, and the longest of both 6-minute walk distances (6MWD) was used for analysis. Only one test was conducted in the second evaluation. The annual rate of change in exercise capacity was defined as the difference between the distance walked at the second evaluation minus that at baseline divided by follow-up time in each subject. Heart rate, oxygen saturation, dyspnoea and fatigue score (Borg scale) ${ }^{27}$ were collected before and at the end of each exercise test. 
At baseline, while on stable conditions, patients also underwent complete lung function tests (forced spirometry, plethysmographic lung volumes, diffusing capacity for carbon monoxide (DLco) and arterial blood gases). Static lung hyperinflation was considered as any value of TLC above $120 \%$ of predicted. ${ }^{28}$ IC/TLC was taken as an index of inspiratory constraint derived from static hyperinflation of the lung. ${ }^{17}$ For analysis, disease severity was classified according to the American Thoracic Society and European Respiratory Society (ATS/ERS) criteria. $^{29}$

Patients also answered a questionnaire that included socio-demographic data, smoking, physical activity, dyspnoea (modified Medical Research Council), comorbidities, health status (St George's Respiratory Questionnaire), anxiety and depression. Information on concomitant medications use, continuous long-term oxygen therapy, participation in pulmonary rehabilitation programmes and exacerbations in the previous year (defined as a worsening of the patient's respiratory symptoms that required a change in medication $)^{30}$ was obtained from medical records. Data on body mass index (BMI), fat free mass index, airway inflammatory markers, serum levels of C-reactive protein and tumour necrosis factor- $\alpha$, cardiac function by Doppler echocardiography, emphysema quantification by High-Resolution Computed Tomography (HRCT), maximum inspiratory and expiratory pressures (MIP and MEP, respectively) and handgrip muscle force were collected at baseline following standardised methodology. Detailed information about the methods, questionnaires, standardisation of the tests, and fieldwork supervision has been previously reported. ${ }^{23}$

\section{Statistical analysis}

Sample size power estimation is detailed in the Online Supplement. 
To account for selective attrition and missing values, we used multiple imputation (20 times) through chained equations. ${ }^{15}$ By performing these analyses all data from 342 PAC-COPD patients were included. Characteristics of study participants using complete cases and imputed datasets have been previously reported. ${ }^{25}$

IC/TLC, as a continuous variable or categorized in tertiles, was selected a priori as the main exposure variable. The bivariate association between IC/TLC, as well as other potential determinants of exercise capacity decline, and change in 6MWD (dependent variable) were analysed using Students' $t$ test or ANOVA, as appropriate depending on the number of categories of the independent variable. Those of them that were significantly related to the outcome were then introduced in a multiple linear regression model to determine the predictors of exercise capacity decline, after adjusting for baseline 6MWD. Variables were kept in the model if they were significantly associated with the outcome and/or they modified (at least by 10\%) the coefficient of other variables in the model. Goodness of fit was assessed by means of normality of residuals, heteroscedasticity, linearity, collinearity and identification of influential data. Because previous research has identified different determinants of exercise capacity in obese and normal weighted COPD patients ${ }^{31}$, we stratified the models according to BMI. Additional analyses using residual volume/total lung capacity (RV/TLC) as a marker of air trapping were also implemented. Finally, sensitivity analyses were conducted (i) using complete case analyses, (ii) measuring changes in the 6MWD as percentage with respect to baseline level, (iii) excluding patients enrolled in pulmonary rehabilitation programs, and (iv) forcing into the model variables previously reported to be associated with 6MWD decline. ${ }^{7,12,13}$ Analysis was conducted using Stata 12.1 (StataCorp, College Station, TX, USA). 


\section{$\underline{\text { RESULTS }}$}

Table 1 shows the main clinical and functional characteristics of the 342 study participants at baseline. Patients were mostly male (92\%) with a mean+SD age of $67.9 \pm 8.6$ years. Airflow limitation was moderate to severe in the majority of patients (mean post-bronchodilator $\mathrm{FEV}_{1}$ was $54 \underline{17 \%}$ of predicted) but there was significant variability. Static hyperinflation was present in 67 (20\%) patients. Thirteen (5\%) patients were enrolled in pulmonary rehabilitation programs, $8(2 \%)$ were on continuous long-term oxygen therapy, and $120(35 \%)$ on chronic inhaled steroids.

Subjects were followed-up for a mean \pm SD of $1.7 \pm 0.34$ years. The mean \pm SD $6 \mathrm{MWD}$ was $433 \pm 93 \mathrm{~m}$ at baseline and $396 \pm 99 \mathrm{~m}$ at the second evaluation. Mean change in 6MWD was $-21.9 \pm 34.1 \mathrm{~m} /$ year.

In the bivariate analysis, patients with higher levels of static hyperinflation (i.e., low IC/TLC) had greater 6MWD decline $(-27.4 \pm 42.5,-24.9 \pm 36.5$ and $-13.4 \pm 39.9 \mathrm{~m} /$ year in the $1^{\text {st }}, 2^{\text {nd }}$ and $3^{\text {rd }}$ tertile of $\mathrm{IC} / \mathrm{TLC}$, respectively; $\mathrm{p}$-for-trend=0.018). From other potential risk factors considered, dyspnoea, health status, serum C-reactive protein and Borg dyspnoea score at the end of the exercise test were related to exercise capacity decline in the bivariate analyses (Figure 1). Other potential determinants did not relate to 6MWD decline (Figures S1, S2 and S3 in the Online Supplementary Information). $\mathrm{FEV}_{1}$ was not associated with exercise capacity decline neither as a continuous nor as a categorical variable. 
In the multivariate regression model (Table 2), only IC/TLC ratio and dyspnoea remained statistically significantly associated with the 6MWD decline, after adjusting for baseline 6MWD. The adjusted predicted change in 6MWD (and 95\% confidence interval) was plotted against IC/TLC ratio (Figure 2), and shows that the lower the baseline IC/TLC ratio, the greater the longitudinal decline in exercise capacity in a linear dose-response shape.

Additional analyses using RV/TLC as a marker of air trapping (Table S1 in Online Supplement), stratification according to BMI (Table S2 in Online Supplement), as well as sensitivity analyses (Table S3, S4, S5 and S6 in Online Supplement) yielded very similar results. Linear regression goodness of fit tests did not reveal any abnormality. 


\section{$\underline{\text { DISCUSSION }}$}

Our study shows that IC/TLC and dyspnoea are associated with 6MWD decline in moderate-to-severe clinically stable COPD patients. However, other variables traditionally considered of clinical relevance in this setting, such as age, BMI or severity of airflow limitation $\left(\mathrm{FEV}_{1}\right)$, did not influence $6 \mathrm{MWD}$ decline in this population once adjusted for selective attrition.

\section{Previous studies}

Three previous studies have investigated factors related to 6MWD decline in COPD. ${ }^{7,12,13}$ Spruit et al. ${ }^{13}$ reported in the ECLIPSE cohort that age, BMI and GOLD grades of airflow limitation were significantly related (after adjustment) with exercise capacity deterioration. In the Bergen COPD cohort, Frisk et al. ${ }^{12}$ found that airflow limitation severity and self-reported physical activity predicted changes in 6MWD in a multivariate regression model. Finally, Casanova et al., ${ }^{7}$ using data from the BODE cohort, found that $6 \mathrm{MWD}$ declined significantly in patients with $\mathrm{FEV}_{1}$ lower than $50 \%$ of predicted, although the association was not adjusted for potentially relevant confounders. None of these studies tested the role of pulmonary function tests other than forced spirometry (i.e., lung volumes or $\mathrm{CO}$ diffusing capacity), systemic inflammation, cardiac function, skeletal muscle force and/or concomitant treatments, among others.

A novel finding of our study is that IC/TLC predicts exercise capacity decline. Lung hyperinflation is frequently observed in patients with COPD. It has potentially negative 
pulmonary and cardiovascular consequences ${ }^{32}$ and is a powerful predictor of mortality in these patients ${ }^{17}$. We add to this knowledge by showing that COPD patients with lower IC/TLC experience a higher longitudinal decline in 6MWD. This is in agreement with previous experimental research that demonstrated that a low IC/TLC predisposes to critical mechanical constraints on tidal volume expansion as ventilatory requirements increase, which in turn results in reduced exercise capacity. ${ }^{16,33}$

Secondly, we found that exertional dyspnoea, a cardinal symptom of patients with $\mathrm{COPD},{ }^{30}$ was also related to the decline in exercise capacity, independently of static hyperinflation. A strong association between dyspnoea and exercise capacity has been reported in previous cross-sectional studies. ${ }^{34}$ Also some interventions, such as pulmonary rehabilitation, result in an improvement of both parameters. ${ }^{1}$ Then, it is plausible that those COPD patients with worse baseline dyspnoea in our study showed a greater decline in exercise capacity.

At variance with previous studies, we did not observe an association between baseline $\mathrm{FEV}_{1}$ and exercise capacity decline. Some explanations can be conceived to interpret this discrepancy including: 1) Differences in patients' characteristics among studies. Our COPD patients walked somewhat more at baseline than those from the ECLIPSE and the BODE cohort (mean $369 \mathrm{~m}$ and $388 \mathrm{~m}$ respectively) and had lower airflow limitation than participants in the BODE cohort (mean $\mathrm{FEV}_{1}=39 \%$ predicted). This fact could have lead to the detection of different determinants of exercise capacity decline. 2) Failure to consider patients lost to follow up in the analysis of previous studies. Between $16 \%$ and $45 \%$ of patients were lost to follow up in these previous studies and 
they were not included in the analysis. Because patients lost to follow up in longitudinal studies usually have poorer health status and lower $\mathrm{FEV}_{1}$ values (as also observed in our PAC-COPD cohort), not including them in the analysis may lead to biased results (usually called survival bias). ${ }^{14}$ Among the several statistical techniques to deal with survival bias, we used multiple imputation. ${ }^{15}$ For didactic purposes, we repeated our analysis with a complete case approach (Figure S4), which resulted in an spurious association between $\mathrm{FEV}_{1}$ and 6MWD decline. Therefore, consideration of patients lost to follow up in longitudinal analyses using appropriate statistical techniques not only prevents missing relevant information, but, most importantly, reduces bias which increases the validity of the estimates. ${ }^{35}$

Also, at difference with Spruit et al., ${ }^{13}$ BMI did not play a role in the 6MWD annual decline in our study patients. This may be partly due to the lack of variability in BMI in our COPD study group, preventing us to detect possible association or interactions with exercise capacity decline. Also, the lack of association between 6MWD decline and participation in pulmonary rehabilitation is likely explained by the reduced number of patients enrolled in such programmes in our study sample $(n=13)$.

\section{Clinical implications}

Timed walking tests, and specially the 6MWD, have been extensively used in the clinical evaluation of patients with COPD, mainly because of their simplicity, reliability and safety. At present, it is recognized that this test adds useful information for the clinical staging of patients (e.g., the BODE index ${ }^{36}$ ). Moreover, longitudinal changes in the $6 \mathrm{MWD}$ are strong predictors of mortality. ${ }^{8-10}$ It is therefore important to identify 
factors associated with this decline in exercise capacity in order to better tailor potential therapeutic interventions, such as pulmonary rehabilitation, that can modify this course. The 2013 ATS/ERS Task Force statement on pulmonary rehabilitation highlights that any individual with chronic respiratory disease could be referred to a pulmonary rehabilitation programme. ${ }^{1}$ However, in real life such programmes are not accessible to many COPD patients from around the world due to the cost-constraint situation in many healthcare systems. Our group previously reported that hospital admissions, frequently observed in COPD patients during the course of their disease, may accelerate the decline of exercise capacity in these patients, ${ }^{25}$ suggesting that patients admitted to a hospital are potential candidates to benefit the most from pulmonary rehabilitation. Our current analysis extends these previous observations and shows that the assessment of clinically stable COPD patients might help clinicians to predict future changes in exercise capacity. We propose that severe dyspnoea and IC/TLC, because of their association with exercise capacity decline, could be used as indicators to prioritise candidates for pulmonary rehabilitation.

Finally, our results might also help to identify those COPD patients who could benefit most from treatments that enable to increase tidal volume during activities, including some drugs and lung volume reduction strategies, thus reducing exertional dyspnoea and interrupting the vicious cycle of worsening exercise capacity. ${ }^{37}$

\section{Strengths and limitations}

The consideration of static volumes and other relevant clinical and functional variables not covered in previous research is a clear strength of our study. Likewise, the large 
cohort of COPD patients (all recruited at the same disease evolution stage) with wide spectrum of disease severity is another strength. Finally, we used multiple imputations to account for selective attrition and missing values, as missing data could have introduced bias in our estimates. ${ }^{14}$ Some limitations of our study, however, should also be noted and discussed. First, even though the PAC-COPD study had no exclusion criteria in relation to sex, few women were included, so we cannot generalise the results to both sexes. Also, since patients were recruited at their first hospitalisation they may not represent the COPD population at large. Finally, only two evaluations were performed during the study period and the time span between them was relatively short $(1.7 \mathrm{y})$.

\section{Conclusions}

IC/TLC and dyspnoea in clinically stable COPD patients predict their exercise capacity decline and may help to guide early therapeutic interventions. 


\section{ACKNOWLEDGEMENTS}

The "Phenotype and Course of COPD (PAC-COPD)" Study Group: Centre for Research in Environmental Epidemiology (CREAL), Barcelona: Josep M Antó (Principal Investigator), Judith Garcia-Aymerich (project coordinator), Marta Benet, Jordi de Batlle, Ignasi Serra, David Donaire-Gonzalez, Stefano Guerra; Hospital del Mar-IMIM, Barcelona: Joaquim Gea (centre coordinator), Eva Balcells, Àngel Gayete, Mauricio Orozco-Levi, Ivan Vollmer; Hospital Clínic-Institut D'Investigacions Biomèdiques August Pi i Sunyer (IDIBAPS), Barcelona: Joan Albert Barberà (centre coordinator), Federico P Gómez, Carles Paré, Josep Roca, Robert Rodriguez-Roisin, Àlvar Agustí, Xavier Freixa, Diego A Rodriguez, Elena Gimeno-Santos, Karina Portillo; Hospital General Universitari Vall D'Hebron, Barcelona: Jaume Ferrer (centre coordinator), Jordi Andreu, Esther Pallissa, Esther Rodríguez; Hospital de la Santa Creu i Sant Pau, Barcelona: Pere Casan (centre coordinator), Rosa Güell, Ana Giménez; Hospital Universitari Germans Trias i Pujol, Badalona: Eduard Monsó (centre coordinator), Alicia Marín, Josep Morera; Hospital Universitari de Bellvitge, Institut d'Investigació Biomèdica de Bellvitge (IDIBELL), L'Hospitalet de Llobregat: Eva Farrero (centre coordinator), Joan Escarrabill; Hospital de Sabadell, Corporació Parc Taulí, Institut Universitari Parc Taulí (Universitat Autònoma de Barcelona), Sabadell: Antoni Ferrer (centre coordinator); Hospital Universitari Son Dureta, Palma de Mallorca: Jaume Sauleda (centre coordinator), Bernat Togores; Hospital Universitario de Cruces, UPV, Barakaldo: Juan Bautista Gáldiz (centre coordinator), Lorena López; Instituto Nacional de Silicosis, Oviedo: José Belda. 
Funding: The PAC-COPD Study is funded by grants from Fondo de Investigación Sanitaria (FIS PI020541), Ministry of Health, Spain; Agència d'Avaluació de Tecnologia i Recerca Mèdiques (AATRM 035/20/02), Catalonia Government; Spanish Society of Pneumology and Thoracic Surgery (SEPAR 2002/137); Catalan Foundation of Pneumology (FUCAP 2003 Beca Marià Ravà); Red RESPIRA (RTIC C03/11); Red RCESP (RTIC C03/09), Fondo de Investigación Sanitaria (PI052486); Fondo de Investigación Sanitaria (PI052302); Fundació La Marató de TV3 (num. 041110); DURSI (2005SGR00392); and unrestricted educational grants from Novartis Farmacèutica, Spain, and AstraZeneca Farmacéutica, Spain. CIBERESP and CIBERES are funded by the Instituto de Salud Carlos III, Ministry of Health, Spain. No involvement of funding sources in study design; in the collection, analysis, and interpretation of data; in the writing of the report; nor in the decision to submit the article for publication. Researchers are independent from funders. 


\section{REFERENCES}

1. Spruit MA, Singh SJ, Garvey C, ZuWallack R, Nici L, Rochester C, Hill K, Holland AE, Lareau SC, Man WD-C, Pitta F, Sewell L, Raskin J, Bourbeau J, Crouch R, Franssen FME, Casaburi R, Vercoulen JH, Vogiatzis I, Gosselink R, Clini EM, Effing TW, Maltais F, van der Palen J, Troosters T, Janssen DJ a, Collins E, Garcia-Aymerich J, Brooks D, Fahy BF. An official American Thoracic Society/European Respiratory Society statement: key concepts and advances in pulmonary rehabilitation. Am Am. J. Respir. Crit. Care Med. 2013; 188: e13-64.

2. Pepin V, Saey D, Laviolette L, Maltais F. Exercise capacity in chronic obstructive pulmonary disease: mechanisms of limitation. COPD. 2007; 4: 195-204.

3. Wijkstra PJ, TenVergert EM, van der Mark TW, Postma DS, Van Altena R, Kraan J, Koëter GH. Relation of lung function, maximal inspiratory pressure, dyspnoea, and quality of life with exercise capacity in patients with chronic obstructive pulmonary disease. Thorax. 1994; 49: 468-72.

4. Spruit MA, Watkins ML, Edwards LD, Vestbo J, Calverley PMA, Pinto-Plata V, Celli BR, Tal-Singer R, Wouters EFM. Determinants of poor 6-min walking distance in patients with COPD: the ECLIPSE cohort. Respir. Med. 2010; 104: 849-57.

5. Oga T, Nishimura K, Tsukino M, Sato S HT. Analysis of the Factors Related to Mortality in Chronic Obstructive Pulmonary Disease Role of Exercise Capacity and Health Status. Am J Respir Crit Care Med. 2003; 167: 544-9.

6. Jones PW. Health status measurement in chronic obstructive pulmonary disease. Thorax. 2001; 56: 880-7.

7. Casanova C, Cote CG, Marin JM, de Torres JP, Aguirre-Jaime A, Mendez R, Dordelly L, Celli BR. The 6-min walking distance: long-term follow up in patients with COPD. Eur. Respir. J. 2007; 29: 535-40. 
8. Cote CG, Pinto-Plata V, Kasprzyk K, Dordelly LJ, Celli BR. The 6-min walk distance, peak oxygen uptake, and mortality in COPD. Chest. 2007; 132; 1778-85.

9. Oga T, Nishimura K, Tsukino M, Sato S, Hajiro T, Mishima M. Exercise capacity deterioration in patients with COPD: longitudinal evaluation over 5 years. Chest. 2005; 128: $62-9$.

10. Pinto-Plata VM, Cote C, Cabral H, Taylor J, Celli BR. The 6-min walk distance: change over time and value as a predictor of survival in severe COPD. Eur. Respir. J. 2004; 23: 28-33.

11. Casaburi R, ZuWallack R. Pulmonary rehabilitation for management of chronic obstructive pulmonary disease. New Engl J Med Clin. 2009: 360: 1329-35.

12. Frisk B, Espehaug B, Hardie JA, Strand LI, Moe-Nilssen R, Eagan TML, Bakke PS, Thorsen E. Physical activity and longitudinal change in 6-min walk distance in COPD patients. Respir. Med. 2014; 108: 86-94.

13. Spruit MA, Polkey MI, Celli B, Edwards LD, Watkins ML, Pinto-Plata V, Vestbo J, Calverley PM a, Tal-Singer R, Agusti A, Coxson HO, Lomas D a, MacNee W, Rennard S, Silverman EK, Crim CC, Yates J, Wouters EFM. Evaluation of COPD Longitudinally to Identify Predictive Surrogate Endpoints (ECLIPSE) study investigators. Predicting outcomes from 6-minute walk distance in chronic obstructive pulmonary disease. J. Am. Med. Dir. Assoc. 2012; 13: 291-7.

14. Hernán MA, Hernández-Díaz S, Robins JM. A structural approach to selection bias. Epidemiology. 2004; 15: 615-25.

15. Van Buuren S, Boshuizen HC, Knook DL. Multiple imputation of missing blood pressure covariates in survival analysis. Stat. Med. 1999; 18: 681-94.

16. O'Donnell DE, Guenette JA, Maltais F, Webb KA. Decline of resting inspiratory capacity in COPD: the impact on breathing pattern, dyspnea, and ventilatory capacity during exercise. Chest. 2012; 141: 753-62. 
17. Casanova C, Cote C, de Torres JP, Aguirre-Jaime A, Marin JM, Pinto-Plata V, Celli BR. Inspiratory-to-total lung capacity ratio predicts mortality in patients with chronic obstructive pulmonary disease. Am. J. Respir. Crit. Care Med. 2005; 171:5917.

18. Tantucci C, Donati P, Nicosia F, Bertellaa E, Redolfia S, De Vecchia M, Cordaa L, Grassia V, Zullia R. Inspiratory capacity predicts mortality in patients with chronic obstructive pulmonary disease. Respir. Med. 2008; 102:613-9.

19. Diaz O, Villafranca C, Ghezzo H, Borzone G, Leiva A, Milic-Emil J, Lisboa C. Role of inspiratory capacity on exercise tolerance in COPD patients with and without tidal expiratory flow limitation at rest. Eur. Respir. J. 2000; 16: 269-75.

20. Albuquerque ALP, Nery LE, Villaça DS, Machado TYS, Oliveira CC, Paes AT, Neder JA. Inspiratory fraction and exercise impairment in COPD patients GOLD stages II-III. Eur. Respir. J. 2006; 28: 939-44.

21. Callens E, Graba S, Gillet-Juvin K, Essalhi M, Bidaud-Chevalier B, Peiffer C, Mahut B, Delclaux C. Measurement of dynamic hyperinflation after a 6-minute walk test in patients with COPD. Chest. 2009; 136: 1466-72.

22. Garcia-Aymerich J, Gómez FP, Benet M, Farrero E, Basagaña X, Gayete À, Paré C, Freixa X, Ferrer J, Ferrer A, Roca J, Gáldiz JB, Sauleda J, Monsó E, Gea J, Barberà J A, Agustí À, Antó JM. Identification and prospective validation of clinically relevant chronic obstructive pulmonary disease (COPD) subtypes. Thorax. 2011; 66: 430-7.

23. Garcia-Aymerich J, Gómez FP, Antó JM. Phenotypic characterization and course of chronic obstructive pulmonary disease in the PAC-COPD Study: design and methods. Arch. Bronconeumol. 2009; 45: 4-11.

24. Balcells E, Antó JM, Gea J, Gómez FP, Rodríguez E, Marin A, Ferrer A, de Batlle J, Farrero E, Benet M, Orozco-Levi M, Ferrer J, Agustí AG, Gáldiz JB, Belda J, GarciaAymerich J. Characteristics of patients admitted for the first time for COPD exacerbation. Respir. Med. 2009; 103: 1293-302. 
25. Ramon MA, Gimeno-Santos E, Ferrer J, Balcells E, Rodríguez E, de Batlle J, Gómez FP, Sauleda J, Ferrer A, Barberà JA, Agustí A, Gea J, Rodriguez-Roisin R, Antó JM, Garcia-Aymerich J. Hospital admissions and exercise capacity decline in patients with COPD. Eur. Respir. J. 2014; 43: 1018-27.

26. ATS statement: guidelines for the six-minute walk test. Am. J. Respir. Crit. Care Med. 2002; 166: 111-7.

27. Borg GA. Psychophysical bases of perceived exertion. Med. Sci. Sports Exerc. 1982; 14: 377-81.

28. Ruppel GL. Lung volumes and gas distribution tests. In: Manual of Pulmonary Function Testing. St Louis, Mosby, 1998; 69-94.

29. Celli BR, MacNee W. Standards for the diagnosis and treatment of patients with COPD: a summary of the ATS/ERS position paper. Eur. Respir. J. 2004; 23: 932-46.

30. Vestbo J, Hurd SS, Agustí AG, Jones PW, Vogelmeier C, Anzueto A, Barnes PJ, Fabbri LM, Martinez FJ, Nishimura M, Stockley RA, Sin DD, Rodriguez-Roisin R. Global strategy for the diagnosis, management, and prevention of chronic obstructive pulmonary disease: GOLD executive summary. Am. J. Respir. Crit. Care Med. 2013; 187: $347-65$.

31. Rodríguez DA, Garcia-Aymerich J, Valera JL, Sauleda J, Togores B, Galdiz JB, Gea J, Orozco-Levi M, Ferrer A, Gomez FP, Barberà JA, Serra I, Antó JM, Roca J. Determinants of exercise capacity in obese and non-obese COPD patients. Respir. Med. 2014; 108: 745-51.

32. O’Donnell DE, Laveneziana P. Dyspnea and activity limitation in COPD: mechanical factors. COPD. 2007; 4:225-36.

33. Guenette J a, Webb K a, O’Donnell DE. Does dynamic hyperinflation contribute to dyspnoea during exercise in patients with COPD? Eur. Respir. J. 2012; 40: 322-9. 
34. Bestall JC, Paul EA, Garrod R, Garnham R, Jones PW, Wedzicha JA. Usefulness of the Medical Research Council (MRC) dyspnoea scale as a measure of disability in patients with chronic obstructive pulmonary disease. Thorax. 1999; 54: 581-6.

35. Donders ART, van der Heijden GJMG, Stijnen T, Moons KGM. Review: a gentle introduction to imputation of missing values. J. Clin. Epidemiol. 2006; 59: 1087-91.

36. Celli BR, Cote CG, Marin JM, Casanova C, Montes de Oca M, Mendez RA, Pinto Plata V, Cabral HJ. The body-mass index, airflow obstruction, dyspnea, and exercise capacity index in chronic obstructive pulmonary disease. N. Engl. J. Med. 2004; 350: $1005-12$.

37. Thomas M, Decramer M, Donnell DEO. No room to breathe: the importance of lung hyperinflation in COPD. Prim Care Respir J. 2013; 22: 101-11. 
Table 1. Characteristics of study participants.

\begin{tabular}{|c|c|}
\hline & $\begin{array}{c}\begin{array}{c}\text { All patients } \\
\mathrm{n}=342\end{array} \\
\end{array}$ \\
\hline \multicolumn{2}{|l|}{ Anthropometric and clinical data } \\
\hline Males & $314(92)$ \\
\hline Age (years) & $67.9 \pm 8.6$ \\
\hline Current smokers & $120(35)$ \\
\hline Active workers & $61(18)$ \\
\hline YPAS physical activity index (score 0 to 137 ) & $34(20-53)$ \\
\hline SGRQ total score ( 0 to 100$)$ & $33(23-48)$ \\
\hline Charlson index $\geq 2, \mathrm{n}(\%)$ & $194(57)$ \\
\hline Body mass index $\left(\mathrm{kg} / \mathrm{m}^{2}\right)$ & $28.2 \pm 4.7$ \\
\hline Fat free mass index $\left(\mathrm{kg} / \mathrm{m}^{2}\right)$ & $19.7+3.1$ \\
\hline mMRC dyspnoea score (0 to 4$)$ & $2(\overline{2-3})$ \\
\hline Exacerbation in previous year $>1^{\dagger}$ & $141(41)$ \\
\hline \multicolumn{2}{|l|}{ Inflammatory markers } \\
\hline Interleukin-6 (pg/ml) & $128(43-259)$ \\
\hline C-reactive protein $(\mathrm{mg} / \mathrm{l})$ & $3.8(1.7-7.1)$ \\
\hline Tumour necrosis factor- $\alpha(\mathrm{pg} / \mathrm{l})$ & $2.1(0.5-10.2)$ \\
\hline \multicolumn{2}{|l|}{ Pulmonary function and blood gases } \\
\hline \multirow{2}{*}{\multicolumn{2}{|c|}{ Airflow limitation severity ${ }^{\ddagger}$}} \\
\hline & \\
\hline Mild $\left(\mathrm{FEV}_{1} \geq 80 \%\right)$ & $19(6)$ \\
\hline Moderate $\left(\overline{F E V} V_{1} \geq 50 \%,<80 \%\right)$ & $164(48)$ \\
\hline Severe $\left(\mathrm{FEV}_{1} \geq 30 \%,<50 \%\right)$ & $132(38)$ \\
\hline Very severe $\left(\overline{F E V}_{1}<30 \%\right)$ & $27(8)$ \\
\hline IC (\% pred) & $67.3 \pm 20.2$ \\
\hline IC/TLC (\%) & $30.9 \pm 9.8$ \\
\hline TLC (\% pred) & $100.4 \pm 18.4$ \\
\hline $\mathrm{RV} / \mathrm{TLC}(\%)$ & $55.9+10.5$ \\
\hline DLco (\% pred) & $64.4 \pm 22.7$ \\
\hline $\mathrm{PaO}_{2}(\mathrm{mmHg})$ & $74.4+10.9$ \\
\hline \multicolumn{2}{|l|}{ Cardiac function } \\
\hline Left Ventricle Ejection Fraction (\%) & $59.0+8.9$ \\
\hline Transtricuspid regurgitant velocity $(\mathrm{m} / \mathrm{sec})$ & $2.4 \pm 0.9$ \\
\hline Right ventricle-Mid end-diastolic diameter (mm) & $31.6+4.5$ \\
\hline \multicolumn{2}{|l|}{ Muscle force and Exercise capacity } \\
\hline Respiratory muscle force (MIP, \%) & $68+27$ \\
\hline Peripheral muscle force (hand-grip, $\mathrm{Kg}$ ) & $30.5 \pm 8.5$ \\
\hline 6MWD at baseline (meters) & $433+93$ \\
\hline 6MWD at follow-up visit (meters) & $396 \pm 99$ \\
\hline Annual change in $6 \mathrm{MWD}$ (meters/year) & $-21.9 \pm 34.1$ \\
\hline
\end{tabular}

Data are presented as $n(\%)$, mean $\_$SD or median $\left(\mathrm{P}_{25}-\mathrm{P}_{75}\right)$. YPAS: Yale physical activity survey; SGRQ: Saint George's respiratory questionnaire; mMRC: modified Medical Research Council dyspnoea scale; $\mathrm{FEV}_{1}$ : forced expiratory volume in 1 second; IC: inspiratory capacity; IC/TLC: inspiratory capacity/total lung capacity; TLC: total lung capacity; RV/TLC: residual volume/total lung capacity; DLco: diffusing capacity for carbon monoxide; $\mathrm{PaO}_{2}$ : arterial oxygen tension; MIP: maximum inspiratory pressure; 6MWD: 6-minute walk distance. *: Descriptive analyses conducted using imputed datasets where existing missing data. Characteristics of study participants at baseline using complete cases and imputed datasets have been previously reported ${ }^{25}$. $\dagger$ : All patients had at least one exacerbation in the previous year, as they were recruited during their first COPD admission. $¥:$ According to the criteria of the ATS/ERS. ${ }^{29}$ 
Table 2. Adjusted predictive factors of exercise capacity decline in 342 COPD patients followed up for 1.7 years.

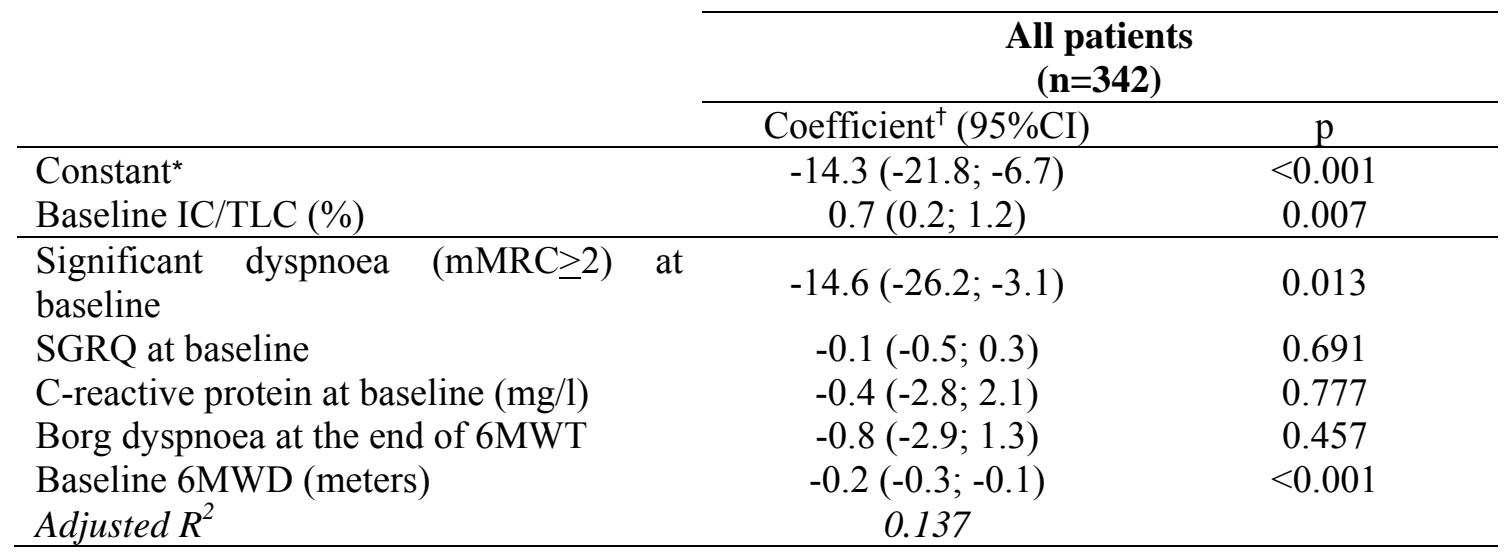

95\% CI: 95\% confidence interval; mMRC: Modified Medical Research Council dyspnoea scale; IC/TLC: inspiratory capacity/total lung capacity; SGRQ: Saint George's respiratory questionnaire; 6MWD: 6-minute walk distance; 6MWT: 6-minute walk test. *: Adjusted mean value based on the linear regression equation corresponding to the mean change in 6-minutes walking distance in a subject with $\mathrm{mMRC}<2$ and mean IC/TLC ratio, SGRQ, C-reactive protein, Borg dyspnoea at the end of 6MWT and mean baseline 6-minute walk distance. Negative values represent decline. + : Coefficients are expressed as changing meters of the sixminute walk distance per (i) each unit of the continuous covariates, or (ii) a change with respect to reference category in categorical covariates. 
Figure 1. Factors associated to the annual change in 6-minute walk distance (6MWD) in 342 COPD patients.
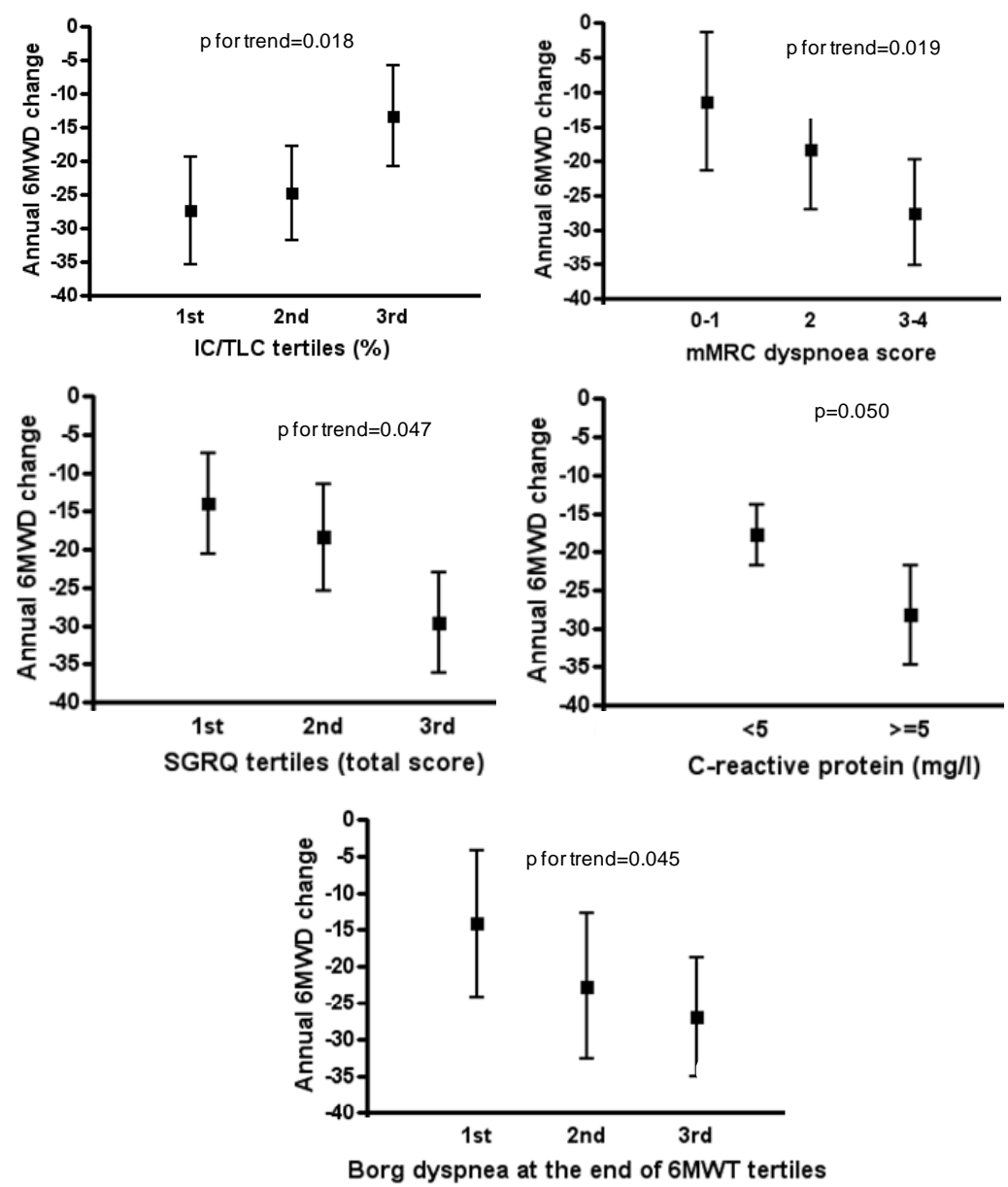

Data are presented as mean and $95 \%$ confidence intervals. Change in 6-minute walk distance is shown in meters/year. Negative values represent decline. 6MWD: 6-minute walk distance; IC/TLC: inspiratory capacity/total lung capacity; mMRC: Modified Medical Research Council dyspnoea scale; SGRQ: Saint George's respiratory questionnaire; 6MWT: 6-minute walk test. 
Figure 2. Mean (and 95\% confidence intervals) annual decline in 6MWD according to IC/TLC. From a linear regression model with IC/TLC as a continuous variable, and adjusted for dyspnoea, quality of life, C-reactive protein, and baseline 6MWD.

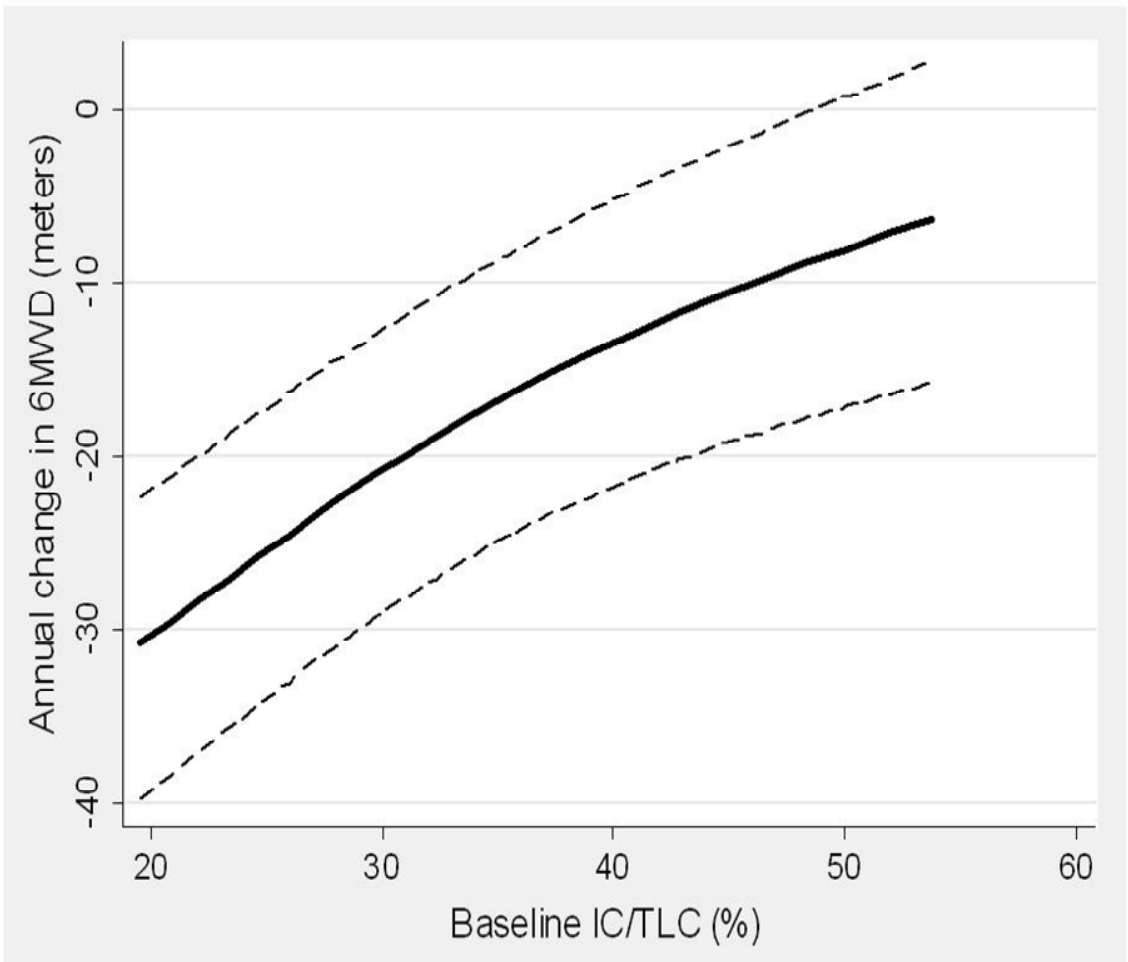




\section{SUPPLEMENTARY INFORMATION}

\section{INSPIRATORY CAPACITY-TO-TOTAL LUNG CAPACITY RATIO AND DYSPNOEA PREDICT EXERCISE CAPACITY DECLINE IN COPD}

Maria A Ramon, Jaume Ferrer, Elena Gimeno-Santos, David Donaire-Gonzalez, Esther Rodríguez, Eva Balcells, Jordi de Batlle, Marta Benet, Stefano Guerra, Jaume Sauleda, Antoni Ferrer, Eva Farrero, Joaquim Gea, Joan A Barberà, Alvar Agustí, Robert Rodriguez-Roisin, Josep M Antó, Judith Garcia-Aymerich, and the PAC-COPD Study Group.

- Methods - Complete version

- Table S1. Adjusted predictive factors of exercise capacity decline in 342 COPD patients followed up for 1.7 years (linear regression model), using RV/TLC as a marker of air trapping.

- Table S2. Adjusted predictive factors of exercise capacity decline in 342 COPD patients followed during 1.7 years (linear regression model), according to baseline BMI.

- Table S3. Adjusted predictive factors of exercise capacity decline in 342 COPD patients followed during 1.7 years (linear regression model), using complete cases and imputed datasets.

- Table S4. Adjusted predictive factors of exercise capacity decline expressed in absolute values and as percentage with respect to baseline level in 342 COPD patients followed during 1.7 years (linear regression model).

- Table S5. Adjusted predictive factors of exercise capacity decline in 342 COPD patients followed during 1.7 years (linear regression model), excluding patients enrolled in pulmonary rehabilitation programs. 
- Table S6. Adjusted predictive factors of exercise capacity decline in 342 COPD patients followed during 1.7 years (linear regression model), forcing variables previously related to 6MWD decline.

- Figure S1. Relationship between relevant socio-demographic, life-style and clinical data and the annual change in 6-minute walk distance (6MWD) in 342 COPD patients.

- Figure S2. Relationship between anxiety and depressive symptoms, lung function parameters, blood gases, muscle force, cardiac function and the annual change in 6minute walk distance (6MWD) in 342 COPD patients.

- Figure S3. Relationship between relevant inflammatory markers, bronchial colonisation and respiratory treatments at baseline and the annual change in 6minute walk distance (6MWD) in 342 COPD patients.

- Figure S4. Relationship between airflow limitation $\left(\mathrm{FEV}_{1}\right)$ and the annual change in 6-minute walk distance (6MWD) in 342 COPD patients, using complete case and multiple imputations strategies.

\section{- Supplement references.}




\section{METHODS- COMPLETE VERSION}

\section{Study design and participants}

Subjects were recruited during their first hospitalization due to a COPD exacerbation in 9 teaching hospitals in Spain between January 2004 and March 2006. The diagnosis of COPD (post-bronchodilator forced expiratory volume in the first second to forced vital capacity ratio $\left.\left(\mathrm{FEV}_{1} / \mathrm{FVC}\right)<0.70\right)$ was confirmed in stable clinical conditions at least 3 months after discharge, during a first evaluation visit. ${ }^{1}$ Following the original protocol, 18 to 24 months (2006-2008) after this first visit, patients were invited to participate in a second evaluation for follow-up assessment. Of the 342 patients originally recruited into the PAC-COPD study $226(66 \%)$ had measures of exercise capacity in the two evaluation visits. Subjects lost to follow-up were older, had more co-morbidities and lower $\mathrm{FEV}_{1}$, as described elsewhere. ${ }^{3}$ The Clinical Research Ethical Committee of all participating hospitals approved the study and written informed consent was obtained from all participants.

\section{Measurements}

Assessments were performed on clinical stability and at least 3 months after discharge. Exercise capacity was assessed by the 6-minute walk test (6MWT). ${ }^{4}$ In the first visit, patients completed two tests with at least a 30-min rest between them, and the longest of both 6-minute walk distances (6MWD) was used for analysis. Only one test was conducted in the second evaluation. The annual rate of change in exercise capacity was defined as the difference between the distance walked at the second evaluation minus that at baseline divided by follow-up time in each subject. Heart rate, oxygen saturation, 
dyspnoea and fatigue score (Borg scale) ${ }^{5}$ were collected before and at the end of each exercise test.

At baseline and in clinical stability, patients underwent complete lung function tests, including forced spirometry (before and after bronchodilator), static lung volumes by whole-body plethysmography, diffusing capacity for carbon monoxide (DLco), arterial blood gases and maximum inspiratory and expiratory pressures (MIP and MEP, respectively). ${ }^{6,7}$ Hyperinflation, according with the classical definition, was considered as any value of total lung capacity (TLC) above $120 \%$ of predicted. ${ }^{8}$ IC/TLC was taken as an index of inspiratory constraint derived from static hyperinflation of the lung. For analysis, disease severity was classified according to the American Thoracic Society and European Respiratory Society (ATS/ERS) criteria. $^{9}$

Patients also answered a computerized epidemiological questionnaire that included socio-demographic data, life-style information, the modified Medical Research Council (mMRC) scale for the assessment of dyspnoea, ${ }^{10}$ and self-reported co-morbid conditions. The Charlson index of comorbidity ${ }^{11}$ was calculated accordingly. Physical activity was assessed using the Yale Physical Activity Survey (YPAS) ${ }^{12}$ in its Spanish version validated for COPD patients. ${ }^{13}$ The validated Spanish-language version ${ }^{14}$ of the St George's Respiratory Questionnaire (SGRQ) ${ }^{15}$ was used to measure health status. Anxiety and depression were assessed using the validated Spanish-language version ${ }^{16}$ of the Hospital Anxiety and Depression Scale (HAD). ${ }^{17}$ Information on concomitant medications use, continuous long-term oxygen therapy, participation in pulmonary rehabilitation programs and exacerbations in the previous year (defined as a worsening 
of the patient's respiratory symptoms that required a change in medication) ${ }^{18}$ were also collected at baseline.

Weight and height were measured and the body mass index (BMI) was calculated and the fat free mass index (FFMI) was obtained by bioimpedance. Data on airway inflammatory markers (interleukin [IL] -1ß, IL-6, IL-8 concentration) and bronchial colonisation were collected and assessed as previously reported. ${ }^{19}$ Serum levels of Creactive protein and tumour necrosis factor- $\alpha$ were also determined, as reported elsewhere. ${ }^{1,19}$ C-reactive protein levels greater than $5 \mathrm{mg} / \mathrm{L}$ were considered as elevated 20. Cardiac function was assessed by Doppler echocardiography following standardized methodology and emphysema quantification was assessed by High-Resolution Computed Tomography (HRCT). ${ }^{21,22}$ Emphysema was defined as sharply delineated low-density areas subdivided into acinar, panlobular or subpleural in both lungs. Emphysema was expressed as a dichotomous variable (presence or absence) Detection of emphysema in any lobe was considered as the presence of emphysema. ${ }^{23} \mathrm{~A}$ hand dynamometer was used to measure peripheral muscle function. Detailed information about the methods, questionnaires, standardization of the tests, and fieldwork supervision has been previously reported. ${ }^{1}$

\section{Statistical analysis}

Sample size of 342 was fixed by the primary scientific objectives of the PAC-COPD Study. ${ }^{22}$ Prior to any analysis we calculated, using the program GRANMO $5.2,{ }^{24}$ that statistical power was $96 \%$ using data from the literature on $6 \mathrm{MWD},{ }^{25,26}$ assuming a 
difference of $40 \mathrm{~m}$ in 6MWD between two equally sized groups, and accepting an alpha risk of 0.05 in a two-sided contrast.

To account for selective attrition and missing values, we used multiple imputation (20 times) through chained equations, replacing missing values by imputations drawn from the predicted distribution of each variable. ${ }^{27}$ By performing these analyses all data from 342 PAC-COPD patients were included. Characteristics of study participants at baseline using complete cases and imputed datasets have been previously reported. ${ }^{3}$ Data are presented as frequencies and percentages for qualitative variables and mean \pm SD for quantitative variables, if not otherwise stated. IC/TLC, as a continuous variable or categorized in tertiles, was selected a priori as the main exposure variable. The bivariate association between static hyperinflation, as well as other potential determinants of exercise capacity decline, and change in 6MWD (dependent variable) were analysed using Students' t test or ANOVA, as appropriate depending on the number of categories of the independent variable. Those of them that were significantly related to the outcome were then introduced in a multiple linear regression model to determine the predictors of exercise capacity decline, after adjusting for baseline 6MWD. Variables were kept in the model if they were significantly associated with the outcome and/or they modified (at least 10\%) the coefficient for other variables in the model. Goodness of fit was assessed by means of normality of residuals, heteroscedasticity, linearity, collinearity and identification of influential data. Because previous research has identified different determinants of exercise capacity in obese and normal weighted COPD patients, ${ }^{28}$ we stratified the models according to BMI. Additional analyses using reserve volume/total lung capacity (RV/TLC) as a marker of air trapping were also 
implemented. Finally, sensitivity analyses were conducted (i) using complete case analyses, (ii) measuring changes in the 6MWD as percentage with respect to baseline level, (iii) excluding patients enrolled in pulmonary rehabilitation programs, and (iv) forcing into the model variables previously related to 6MWD decline. ${ }^{29-31}$ Analysis was conducted using Stata 12.1 (StataCorp, College Station, TX, USA). A p $<0.05$ was considered significant. 
Table S1. Adjusted predictive factors of exercise capacity decline in 342 COPD patients followed up for 1.7 years (linear regression model), using RV/TLC as a marker of air trapping.

\begin{tabular}{|c|c|c|c|c|}
\hline & \multicolumn{2}{|c|}{$\begin{array}{c}\text { Using RV/TLC as a market of } \\
\text { air trapping } \\
(\mathbf{n}=\mathbf{3 4 2})\end{array}$} & \multicolumn{2}{|c|}{$\begin{array}{l}\text { Using IC/TLC as a market of } \\
\text { lung hyperinflation } \\
(n=342)\end{array}$} \\
\hline & Coefficient $^{\dagger}(95 \% \mathrm{CI})$ & $\mathrm{p}$ & Coefficient $^{\dagger}(95 \% \mathrm{CI})$ & $\mathrm{p}$ \\
\hline Constant* & $-14.1(-21.7 ;-6.6)$ & 0.001 & $-14.3(-21.8 ;-6.7)$ & $<0.001$ \\
\hline Baseline RV/TLC (\%) & $-0.7(-1.2 ;-0.1)$ & 0.016 & -- & -- \\
\hline Baseline IC/TLC (\%) & -- & -- & $0.7(0.2 ; 1.2)$ & 0.007 \\
\hline $\begin{array}{l}\text { Significant dyspnoea }(\mathrm{mMRC} \geq 2) \text { at } \\
\text { baseline }\end{array}$ & $-14.6(-26.1 ;-3.2)$ & 0.012 & $-14.6(-26.2 ;-3.1)$ & 0.013 \\
\hline SGRQ at baseline & $-0.1(-0.5 ; 0.2)$ & 0.503 & $-0.1(-0.5 ; 0.3)$ & 0.691 \\
\hline C-reactive protein at baseline $(\mathrm{mg} / \mathrm{l})$ & $-0.11(-2.6 ; 2.3)$ & 0.928 & $-0.4(-2.8 ; 2.1)$ & 0.777 \\
\hline Borg dyspnoea at the end of $6 \mathrm{MWT}$ & $-1.2(-8.2 ; 5.6)$ & 0.742 & $-0.8(-2.9 ; 1.3)$ & 0.457 \\
\hline Baseline 6MWD (meters) & $-0.2(-0.3 ;-0.1)$ & $<0.001$ & $-0.2(-0.3 ;-0.1)$ & $<0.001$ \\
\hline Adjusted $R^{2}$ & 0.134 & & 0.137 & \\
\hline
\end{tabular}

Definition of abbreviation: $95 \% \mathrm{CI}=95 \%$ confidence interval; $\mathrm{mMRC}=$ Modified Medical Research Council dyspnoea scale; RV/TLC= residual volume/total lung capacity; IC/TLC= inspiratory capacity/total lung capacity; $\mathrm{SGRQ}=$ Saint George's respiratory questionnaire $6 \mathrm{MWD}=6$-minute walk distance; $6 \mathrm{MWT}=$ 6-minute walk test.

*Adjusted mean value based on the linear regression equation corresponding to the mean change in 6-minutes walking distance in a subject with mMRC $<2$ and mean RV/TLC ratio (or mean IC/TLC), SGRQ, C-reactive protein, Borg dyspnoea at the end of 6MWT and mean baseline 6-minute walk distance. Negative values represent decline.

†Coefficients are expressed as changing meters of the six-minute walk distance per (i) each unit of the continuous covariates, or (ii) a change with respect to reference category in categorical covariates. 
Table S2. Adjusted predictive factors of exercise capacity decline in 342 COPD patients followed during 1.7 years (linear regression model), according to baseline BMI.

\begin{tabular}{|c|c|c|c|c|}
\hline & \multicolumn{2}{|c|}{$\begin{array}{c}\text { BMI }<30 \text { kg.m }{ }^{-2} \\
(n=221)\end{array}$} & \multicolumn{2}{|c|}{$\begin{array}{c}\text { BMI } \geq 30 \text { kg.m } \\
(\mathbf{n}=121)\end{array}$} \\
\hline & $\begin{array}{c}\text { Coefficient }^{\dagger} \\
(95 \% \mathrm{CI})\end{array}$ & $\mathrm{p}$ & $\begin{array}{l}\text { Coefficient }^{\dagger} \\
(95 \% \mathrm{CI})\end{array}$ & $\mathrm{p}$ \\
\hline Constant $^{\star}$ & $-11.7(-22.5 ;-1.0)$ & 0.035 & $-11.8(-31.2 ; 7.4)$ & 0.223 \\
\hline Baseline IC/TLC (\%) & $0.9(0.3 ; 1.6)$ & 0.006 & $0.6(-0.3 ; 1.6)$ & 0.196 \\
\hline $\begin{array}{l}\text { Significant dyspnoea }(\mathrm{mMRC} \geq 2) \text { at } \\
\text { baseline }\end{array}$ & $-15.7(-29.2 ;-2.2)$ & 0.028 & $-15.0(-35.8 ; 5.7)$ & 0.154 \\
\hline SGRQ at baseline & $-0.2(-0.6 ; 0.26)$ & 0.430 & $0.1(-0.68 ; 0.77)$ & 0.910 \\
\hline C-reactive protein at baseline $(\mathrm{mg} / \mathrm{l})$ & $-0.2(-4.0 ; 3.7)$ & 0.938 & $0.4(-3.2 ; 3.9)$ & 0.855 \\
\hline Borg dyspnoea at the end of $6 \mathrm{MWT}$ & $0.2(-2.3 ; 2.7)$ & 0.882 & $-1.7(-5.6 ; 2.2)$ & 0.385 \\
\hline Baseline 6MWD (meters) & $-0.2(-0.2 ;-0.1)$ & 0.002 & $-0.2(-0.3 ;-0.1)$ & 0.008 \\
\hline Adjusted $R^{2}$ & 0.165 & & 0.120 & \\
\hline
\end{tabular}

Definition of abbreviation: $95 \% \mathrm{CI}=95 \%$ confidence intervals; IC/TLC $=$ inspiratory capacity/total lung capacity; $\mathrm{mMRC}=$ Modified Medical Research Council dyspnoea scale; SGRQ= Saint George's respiratory questionnaire $6 \mathrm{MWD}=6$-minute walk distance.

*Adjusted mean value based on the linear regression equation corresponding to the mean change in 6-minutes walking distance in a subject with $\mathrm{mMRC}<2$ and mean IC/TLC ratio, SGRQ, C-reactive protein, Borg dyspnoea at the end of 6MWT and mean baseline six-minute walk distance. Negative values represent decline.

${ }^{\dagger}$ Coefficients are expressed as changing meters of the six-minute walk distance per (i) each unit of the continuous covariates, or (ii) a change with respect to reference category in categorical covariates. 
Table S3. Adjusted predictive factors of exercise capacity decline in 342 COPD patients followed during 1.7 years (linear regression model), using complete cases and imputed datasets.

\begin{tabular}{|c|c|c|c|c|}
\hline & \multicolumn{2}{|c|}{$\begin{array}{c}\text { Complete cases } \\
\qquad(\mathrm{n}=\mathbf{2 2 6})\end{array}$} & \multicolumn{2}{|c|}{$\begin{array}{l}\text { Multiple imputation } \\
\qquad(\mathrm{n}=\mathbf{3 4 2})\end{array}$} \\
\hline & Coefficient $^{\dagger}(95 \% \mathrm{CI})$ & $\mathrm{p}$ & Coefficient $^{\dagger}(95 \% \mathrm{CI})$ & $\mathrm{p}$ \\
\hline Constant $^{*}$ & $-14.8(-22.1 ;-7.4)$ & $<0.001$ & $-14.3(-21.8 ;-6.7)$ & $<0.001$ \\
\hline Baseline RV/TLC (\%) & $0.8(0.3 ; 1.4)$ & 0.003 & $0.7(0.2 ; 1.2)$ & 0.007 \\
\hline $\begin{array}{l}\text { Significant dyspnoea }(\mathrm{mMRC} \geq 2) \text { at } \\
\text { baseline }\end{array}$ & $-9.4(-21.9 ; 3.1)$ & 0.140 & $-14.6(-26.2 ;-3.1)$ & 0.013 \\
\hline SGRQ at baseline & $-0.1(-0.5 ; 0.2)$ & 0.639 & $-0.1(-0.5 ; 0.3)$ & 0.691 \\
\hline C-reactive protein at baseline (mg/l) & $-0.1(-2.6 ; 2.5)$ & 0.928 & $-0.4(-2.8 ; 2.1)$ & 0.777 \\
\hline Borg dyspnoea at the end of $6 \mathrm{MWT}$ & $-1.7(-3.9 ; 0.5)$ & 0.101 & $-0.8(-2.9 ; 1.3)$ & 0.457 \\
\hline Baseline 6MWD (meters) & $-0.1(-0.2 ;-0.1)$ & $<0.001$ & $-0.2(-0.3 ;-0.1)$ & $<0.001$ \\
\hline Adjusted $R^{2}$ & 0.101 & & 0.137 & \\
\hline
\end{tabular}

Definition of abbreviation: $95 \% \mathrm{CI}=95 \%$ confidence interval; IC/TLC $=$ inspiratory capacity/total lung capacity; mMRC $=$ Modified Medical Research Council dyspnoea scale; SGRQ= Saint George's respiratory questionnaire 6MWD= 6-minute walk distance.

*Adjusted mean value based on the linear regression equation corresponding to the mean change in 6-minutes walking distance in a subject with mMRC $<2$ and mean IC/TLC ratio, SGRQ, C-reactive protein, Borg dyspnoea at the end of 6MWT and mean baseline 6-minute walk distance. Negative values represent decline.

${ }^{\dagger}$ Coefficients are expressed as changing meters of the six-minute walk distance per (i) each unit of the continuous covariates, or (ii) a change with respect to reference category in categorical covariates. 
Table S4. Adjusted predictive factors of exercise capacity decline expressed in absolute values and as percentage with respect to baseline level in 342 COPD patients followed during 1.7 years (linear regression model).

\begin{tabular}{|c|c|c|c|c|}
\hline & \multicolumn{2}{|c|}{$\begin{array}{l}\text { 6MWD decline, meters } \\
\qquad(\mathrm{n}=342)\end{array}$} & \multicolumn{2}{|c|}{$\begin{array}{l}\text { 6MWD decline, \% from baseline } \\
\qquad(\mathrm{n}=342)\end{array}$} \\
\hline & Coefficient $^{\dagger}(95 \% \mathrm{CI})$ & $\mathrm{p}$ & Coefficient $^{\dagger}(95 \% \mathrm{CI})$ & $\mathrm{p}$ \\
\hline Constant $^{*}$ & $-14.3(-21.8 ;-6.7)$ & $<0.001$ & $-2.15(-4.98 ; 0.68)$ & 0.133 \\
\hline Baseline IC/TLC (\%) & $0.7(0.2 ; 1.2)$ & 0.007 & $0.14(0.11 ; 0.18)$ & 0.045 \\
\hline $\begin{array}{l}\text { Significant dyspnoea }(\mathrm{mMRC} \geq 2) \text { at } \\
\text { baseline }\end{array}$ & $-14.6(-26.2 ;-3.1)$ & 0.013 & $-5.00(-9.48 ;-0.71)$ & 0.023 \\
\hline SGRQ at baseline & $-0.1(-0.5 ; 0.3)$ & 0.691 & $0.02(-0.13 ; 0.16)$ & 0.825 \\
\hline C-reactive protein at baseline $(\mathrm{mg} / \mathrm{l})$ & $-0.4(-2.8 ; 2.1)$ & 0.777 & $0.14(-0.92 ; 1.19)$ & 0.792 \\
\hline Borg dyspnoea at the end of $6 \mathrm{MWT}$ & $-0.8(-2.9 ; 1.3)$ & 0.457 & $-0.02(-0.76 ; 0.73)$ & 0.966 \\
\hline Baseline 6MWD (meters) & $-0.2(-0.3 ;-0.1)$ & $<0.001$ & $-0.04(-0.04 ;-0.03)$ & $<0.001$ \\
\hline Adjusted $R^{2}$ & 0.137 & & 0.080 & \\
\hline
\end{tabular}

Definition of abbreviation: $95 \% \mathrm{CI}=95 \%$ confidence interval; IC/TLC $=$ inspiratory capacity/total lung capacity; mMRC $=$ Modified Medical Research Council dyspnoea scale; SGRQ= Saint George's respiratory questionnaire 6MWD= 6-minute walk distance.

*Adjusted mean value based on the linear regression equation corresponding to the mean change in 6-minutes walking distance in a subject with mMRC $<2$, and mean IC/TLC ratio, SGRQ, C-reactive protein, Borg dyspnoea at the end of 6MWT and mean baseline 6-minute walk distance. Negative values represent decline.

${ }^{\dagger}$ Coefficients are expressed as changing meters of the six-minute walk distance per (i) each unit of the continuous covariates, or (ii) a change with respect to reference category in categorical covariates. 
Table S5. Adjusted predictive factors of exercise capacity decline in 342 COPD patients followed during 1.7 years (linear regression model), excluding patients enrolled in pulmonary rehabilitation programs.

\begin{tabular}{|c|c|c|c|c|}
\hline & \multicolumn{2}{|l|}{$\begin{array}{l}\text { All patients } \\
\qquad(\mathrm{n}=\mathbf{3 4 2})\end{array}$} & \multicolumn{2}{|c|}{$\begin{array}{c}\text { Patient not enrolled in } \\
\text { pulmonary rehabilitation } \\
(\mathrm{n}=329)\end{array}$} \\
\hline & Coefficient $^{\dagger}(95 \% \mathrm{CI})$ & $\mathrm{p}$ & Coefficient $^{\dagger}(95 \% \mathrm{CI})$ & $\mathrm{p}$ \\
\hline Constant $^{*}$ & $-14.3(-21.8 ;-6.7)$ & $<0.001$ & $-11.3(-20.6 ;-1.9)$ & 0.018 \\
\hline Baseline RV/TLC (\%) & $0.7(0.2 ; 1.2)$ & 0.007 & $0.9(0.4 ; 1.4)$ & 0.001 \\
\hline $\begin{array}{l}\text { Significant dyspnoea }(\mathrm{mMRC} \geq 2) \text { at } \\
\text { baseline }\end{array}$ & $-14.6(-26.2 ;-3.1)$ & 0.013 & $-11.8(-24.0 ; 0.4)$ & 0.052 \\
\hline SGRQ at baseline & $-0.1(-0.5 ; 0.3)$ & 0.691 & $-0.1(-0.5 ; 0.3)$ & 0.522 \\
\hline C-reactive protein at baseline (mg/l) & $-0.4(-2.8 ; 2.1)$ & 0.777 & $0.1(-2.6 ; 2.8)$ & 0.934 \\
\hline Borg dyspnoea at the end of 6MWT & $-0.8(-2.9 ; 1.3)$ & 0.457 & $-1.0(-3.2 ; 1.1)$ & 0.352 \\
\hline Baseline 6MWD (meters) & $-0.2(-0.3 ;-0.1)$ & $<0.001$ & $-0.1(-0.2 ;-0.1)$ & $<0.001$ \\
\hline Adjusted $R^{2}$ & 0.137 & & 0.156 & \\
\hline
\end{tabular}

Definition of abbreviation: $95 \% \mathrm{CI}=95 \%$ confidence interval; IC/TLC $=$ inspiratory capacity /total lung capacity; mMRC $=$ Modified Medical Research Council dyspnoea scale; SGRQ= Saint George's respiratory questionnaire $6 \mathrm{MWD}=6$-minute walk distance.

*Adjusted mean value based on the linear regression equation corresponding to the mean change in 6-minutes walking distance in a subject with $\mathrm{mMRC}<2$, and mean IC/TLC ratio, SGRQ, C-reactive protein, Borg dyspnoea at the end of 6MWT and mean baseline 6-minute walk distance. Negative values represent decline. ${ }^{\dagger}$ Coefficients are expressed as changing meters of the six-minute walk distance per (i) each unit of the continuous covariates, or (ii) a change with respect to reference category in categorical covariates. 
Table S6. Adjusted predictive factors of exercise capacity decline in 342 COPD patients followed during 1.7 years (linear regression model), forcing variables previously related to 6MWD decline.

Original model
Model after forcing variables

previously related to $6 \mathrm{MWD}$

decline

$(\mathbf{n}=\mathbf{3 4 2})$

\begin{tabular}{lcccc} 
& Coefficient $^{\dagger}(95 \% \mathrm{CI})$ & $\mathrm{p}$ & Coefficient $^{\dagger}(95 \% \mathrm{CI})$ & $\mathrm{p}$ \\
\hline Constant $^{\star}$ & $-14.3(-21.8 ;-6.7)$ & $<0.001$ & $-14.4(-22.3 ;-6.5)$ & $<0.001$ \\
Baseline RV/TLC $(\%)$ & $0.7(0.2 ; 1.2)$ & 0.007 & $0.9(0.3 ; 1.6)$ & 0.007 \\
\hline $\begin{array}{l}\text { Significant dyspnoea }(\mathrm{mMRC} \geq 2) \text { at } \\
\text { baseline }\end{array}$ & $-14.6(-26.2 ;-3.1)$ & 0.013 & $-13.8(-25.3 ;-2.3)$ & 0.019 \\
SGRQ at baseline & $-0.1(-0.5 ; 0.3)$ & 0.691 & $-0.2(-0.6 ; 0.2)$ & 0.361 \\
C-reactive protein at baseline (mg/l) & $-0.4(-2.8 ; 2.1)$ & 0.777 & $-0.3(-2.8 ; 2.2)$ & 0.826 \\
Borg dyspnoea at the end of 6MWT & $-0.8(-2.9 ; 1.3)$ & 0.457 & $-0.7(-2.9 ; 1.6)$ & 0.560 \\
Baseline 6MWD (meters) & $-0.2(-0.3 ;-0.1)$ & $<0.001$ & $-0.2(-0.3 ;-0.1)$ & $<0.001$ \\
Age at baseline & -- & -- & $-0.7(-1.4 ;-0.1)$ & 0.037 \\
Body Mass Index (Kg/m $\left.{ }^{2}\right)$ & -- & -- & $-0.3(-1.5 ; 0.9)$ & 0.657 \\
FEV ${ }_{1}(\%$ pred) & -- & -- & $0.1(-0.6 ; 0.5)$ & 0.515 \\
YPAS physical activity index & -- & $-0.1(-0.3 ; 0.1)$ & 0.303 \\
\multicolumn{1}{c}{ Adjusted $\boldsymbol{R}^{2}$} & 0.137 & & 0.164 &
\end{tabular}

Definition of abbreviation: $95 \% \mathrm{CI}=95 \%$ confidence interval; IC/TLC $=$ inspiratory capacity /total lung capacity; $\mathrm{mMRC}=$ Modified Medical Research Council dyspnoea scale; SGRQ= Saint George's respiratory questionnaire $6 \mathrm{MWD}=6$-minute walk distance; $\mathrm{FEV}_{1}=$ forced expiratory volume in 1 second; YPAS=Yale physical activity survey.

*Adjusted mean value based on the linear regression equation corresponding to the mean change in 6-minutes walking distance in a subject with $\mathrm{mMRC}<2$, and mean IC/TLC ratio, SGRQ, C-reactive protein, Borg dyspnoea at the end of 6MWT, 6-minute walk distance, age, Body Mass Index, FEV Fnd $_{1}$ mean baseline YPAS physical activity index. Negative values represent decline.

${ }^{\dagger}$ Coefficients are expressed as changing meters of the six-minute walk distance per (i) each unit of the continuous covariates, or (ii) a change with respect to reference category in categorical covariates. 
Figure S1. Relationship between relevant socio-demographic, life-style and clinical data and the annual change in 6-minute walk distance (6MWD) in 342 COPD patients.

Data are presented as mean and 95\% confidence intervals. Change in 6-minute walk distance is shown in meters/year. Definition of abbreviation: 6MWD: 6-minute walk distance; YPAS: Yale physical Activity Survey; BMI: Body Mass Index; HRCT: High-Resolution Computed Tomography. *All patients had at least one exacerbation in the previous year, as they were recruited during their first COPD admission. "Emphysema was defined as sharply delineated low-density areas subdivided into acinar, panlobular or subpleural in both lungs. 
Figure S2. Relationship between anxiety and depressive symptoms, lung function parameters, blood gases, muscle force, cardiac function and the annual change in 6minute walk distance (6MWD) in 342 COPD patients.

Data are presented as mean and $95 \%$ confidence intervals. Change in 6-minute walk distance is shown in meters/year. Definition of abbreviation: $6 \mathrm{MWD}=6$-minute walk distance; HADS=Hospital Anxiety and Depression Scale; $\mathrm{FEV}_{1}=$ forced expiratory volume in 1 second; DLco= diffusing capacity for carbon monoxide; $\mathrm{PaO}_{2}=$ arterial oxygen tension; $\mathrm{MIP}=$ maximum inspiratory pressure. 
Figure S3. Relationship between relevant inflammatory markers, bronchial colonisation and respiratory treatments at baseline and the annual change in 6-minute walk distance (6MWD) in 342 COPD patients.

Data are presented as mean and 95\% confidence intervals. Change in 6-minute walk distance is shown in meters/year. Definition of abbreviation: 6MWD: 6-minute walk distance; TNF: Tumour necrosis factor. *Alone or in combination with other drug treatments; 'Defined as some kind of long-acting beta adrenergic, corticosteroids, or a combination of both. 
Figure S4. Relationship between airflow limitation $\left(\mathrm{FEV}_{1}\right)$ and the annual change in 6-minute walk distance (6MWD) in 342 COPD patients, using complete case and multiple imputations strategies.

Data are presented as mean and $95 \%$ coefficient intervals.

Definition of abbreviations: $\mathrm{FEV}_{1}=$ forced espiratory volume in 1 second; $6 \mathrm{MWD}=6$-minute walk distance. 


\section{SUPPLEMENT REFERENCES}

1. Garcia-Aymerich J, Gómez FP, Antó JM. Phenotypic characterization and course of chronic obstructive pulmonary disease in the PAC-COPD Study: design and methods. Arch. Bronconeumol.2009; 45: 4-11.

2. Balcells E, Antó JM, Gea J, Gómez FP, Rodríguez E, Marin A, Ferrer A, de Batlle J, Farrero E, Benet M, Orozco-Levi M, Ferrer J, Agustí AG, Gáldiz JB, Belda J, GarciaAymerich J. Characteristics of patients admitted for the first time for COPD exacerbation. Respir. Med. 2009; 103: 1293-302.

3. Ramon MA, Gimeno-Santos E, Ferrer J, Balcells E, Rodríguez E, de Batlle J, Gómez FP, Sauleda J, Ferrer A, Barberà J a, Agustí A, Gea J, Rodriguez-Roisin R, Antó JM, Garcia-Aymerich J. Hospital admissions and exercise capacity decline in patients with COPD. Eur. Respir. J. 2014; 43: 1018-27.

4. ATS statement: Guidelines for the six-minute walk test. Am. J. Respir. Crit. Care Med. 2002; 166: 111-7.

5. Borg GA. Psychophysical bases of perceived exertion. Med. Sci. Sports Exerc. 1982; 14: $377-81$.

6. Manual SEPAR de Procedimientos. Módulo 3. Procedimientos de evaluación de la función pulmonar. Madrid: Ediciones Luzán SA; 2002.

7. Manual SEPAR de Procedimientos. Módulo 4. Procedimientos de evaluacón de la función pulmonar-II. Barcelona: Publicaciones Permanyer; 2004.

8. Ruppel GL. Lung volumes and gas distribution tests. In: Manual of Pulmonary Function Testing. St Louis, Mosby, 1998; 69-94.

9. Celli BR, MacNee W. Standards for the diagnosis and treatment of patients with COPD: a summary of the ATS/ERS position paper. Eur. Respir. J. 2004; 23: 932-46.

10. Surveillance for respiratory hazards in the occupational setting [American Thoracic Society]. Am. Rev. Respir. Dis. 1982; 126: 952-6.

11. Charlson M, Szatrowski TP, Peterson J, Gold J. Validation of a combined comorbidity index. J. Clin. Epidemiol. 1994; 47: 1245-51.

12. Dipietro L, Caspersen CJ, Ostfeld AM, Nadel ER. A survey for assessing physical activity among older adults. Med. Sci. Sports Exerc. 1993; 25: 628-42.

13. Donaire-Gonzalez D, Gimeno-Santos E, Serra I, Roca J, Balcells E, Rodríguez E, Farrero E, Antó JM, Garcia-Aymerich J. [Validation of the Yale Physical Activity Survey in chronic obstructive pulmonary disease patients]. Arch. Bronconeumol.2011; 47: 552-60. 
14. Ferrer M, Alonso J, Prieto L, Plaza V, Monsó E, Marrades R, Aguar MC, Khalaf A, Antó JM. Validity and reliability of the St George's Respiratory Questionnaire after adaptation to a different language and culture: the Spanish example. Eur. Respir. J. 1996; 9: 1160-6.

15. Jones PW, Quirk FH, Baveystock CM. The St George's Respiratory Questionnaire. Respir. Med. 1991; 85 Suppl B: 25-31.

16. Quintana JM, Padierna A, Esteban C, Arostegui I, Bilbao A, Ruiz I. Evaluation of the psychometric characteristics of the Spanish version of the Hospital Anxiety and Depression Scale. Acta Psychiatr. Scand. 2003; 107: 216-21.

17. Zigmond AS, Snaith RP. The hospital anxiety and depression scale. Acta Psychiatr. Scand. 1983; 67: 361-70.

18. Vestbo J, Hurd SS, Agustí AG, Jones PW, Vogelmeier C, Anzueto A, Barnes PJ, Fabbri LM, Martinez FJ, Nishimura M, Stockley RA, Sin DD, Rodriguez-Roisin R. Global strategy for the diagnosis, management, and prevention of chronic obstructive pulmonary disease: GOLD executive summary. Am. J. Respir. Crit. Care Med. 2013; 187: $347-65$.

19. Marin A, Garcia-Aymerich J, Sauleda J, Belda J, Millares L, García-Núñez M, Serra I, Benet M, Agustí A, Antó JM, Monsó E. Effect of bronchial colonisation on airway and systemic inflammation in stable COPD. COPD 2012; 9: 121-30.

20. Pearson TA, Mensah GA, Alexander RW, Anderson JL, Cannon RO, Criqui M, Fadl YY, Fortmann SP, Hong Y, Myers GL, Rifai N, Smith SC, Taubert K, Tracy RP, Vinicor F. Markers of inflammation and cardiovascular disease: application to clinical and public health practice: A statement for healthcare professionals from the Centers for Disease Control and Prevention and the American Heart Association. Circulation 2003; 107: 499-511.

21. Freixa X, Portillo K, Paré C, Garcia-Aymerich J, Gomez FP, Benet M, Roca J, Farrero E, Ferrer J, Fernandez-Palomeque C, Antó JM, Barberà JA. Echocardiographic abnormalities in patients with COPD at their first hospital admission. Eur. Respir. J. 2013; 41: 784-91.

22. Garcia-Aymerich J, Gómez FP, Benet M, Farrero E, Basagaña X, Gayete À, Paré C, Freixa X, Ferrer J, Ferrer A, Roca J, Gáldiz JB, Sauleda J, Monsó E, Gea J, Barberà J a, Agustí À, Antó JM. Identification and prospective validation of clinically relevant chronic obstructive pulmonary disease (COPD) subtypes. Thorax 2011; 66: 430-7.

23. Rodríguez E, Ferrer J, Zock J-P, Serra I, Antó JM, de Batlle J, Kromhout H, Vermeulen R, Donaire-González D, Benet M, Balcells E, Monsó E, Gayete A, GarciaAymerich J. Lifetime occupational exposure to dusts, gases and fumes is associated with bronchitis symptoms and higher diffusion capacity in COPD patients. PLoS One 2014; 9: e88426. 
24. Marrugat J, Vila J, Pavesi M, Sanz F. [Estimation of the sample size in clinical and epidemiological investigations]. Med. Clin. (Barc). 1998; 111: 267-76.

25. Troosters T, Gosselink R, Decramer M. Six minute walking distance in healthy elderly subjects. Eur. Respir. J. 1999; 14: 270-4.

26. Gibbons WJ, Fruchter N, Sloan S, Levy RD. Reference values for a multiple repetition 6-minute walk test in healthy adults older than 20 years. J. Cardiopulm.

Rehabil. 2001; 21: 87-93.

27. Van Buuren S, Boshuizen HC, Knook DL. Multiple imputation of missing blood pressure covariates in survival analysis. Stat. Med. 1999; 18: 681-94.

28. Rodríguez DA, Garcia-Aymerich J, Valera JL, Sauleda J, Togores B, Galdiz JB, Gea J, Orozco-Levi M, Ferrer A, Gomez FP, Barberà JA, Serra I, Antó JM, Roca J. Determinants of exercise capacity in obese and non-obese COPD patients. Respir. Med. 2014; 108: 745-51.

29. Frisk B, Espehaug B, Hardie JA, Strand LI, Moe-nilssen R, Eagan TML, Bakke PS, Thorsen E. Physical activity and longitudinal change in 6-min walk distance in COPD patients. Respir. Med. 2014; 108: 86-94.

30. Casanova C, Cote CG, Marin JM, de Torres JP, Aguirre-Jaime a, Mendez R, Dordelly L, Celli BR. The 6-min walking distance: long-term follow up in patients with COPD. Eur. Respir. J. 2007; 29: 535-40.

31. Spruit M a, Polkey MI, Celli B, Edwards LD, Watkins ML, Pinto-Plata V, Vestbo J, Calverley PM a, Tal-Singer R, Agusti A, Coxson HO, Lomas D a, MacNee W, Rennard S, Silverman EK, Crim CC, Yates J, Wouters EFM. Predicting outcomes from 6-minute walk distance in chronic obstructive pulmonary disease. J. Am. Med. Dir. Assoc. 2012; 13: $291-7$. 